\title{
A ASSOCIAÇÃO DE UM ATRAENTE SINTÉTICO AO PANO PRETO IMPREGNADO COM Metarhizium anisopliae AUMENTA TAXA DE INFECÇÃO DE Aedes aegypti
}

\author{
Leila Eid Imad da Silva ${ }^{1}$ \\ Adriano Rodrigues de Paula ${ }^{2}$ \\ Anderson Ribeiro ${ }^{3}$ \\ Richard lan Samuels ${ }^{4}$
}

Resumo: Neste estudo foi desenvolvido um novo método de controle do mosquito Aedes aegypti utilizando armadilha PET com pano preto impregnado com fungo entomopatogênico Metarhizium anisopliae associado a um atraente sintético. Os experimentos foram realizados em salas simulando cômodos residenciais de $6 \mathrm{~m}^{2}$. As armadilhas PET foram colocadas embaixo de mesas e cadeiras dentro das salas. Cinqüenta fêmeas do mosquito foram liberadas nas salas e 5 dias depois, uma armadilha para captura de mosquitos vivos (BG-Sentinel) foi colocada nas salas. Os mosquitos expostos a uma armadilha PET com pano preto + M. anisopliae + atraente apresentaram menor taxa de sobrevivência $(32,6 \%)$ comparada com a sobrevivência de insetos expostos a uma armadilha PET com: pano preto + M. anisopliae (48\%), somente pano preto + atraente (80\%) e somente pano preto + água estéril (82\%). Esta armadilha apresenta vantagens por ser confeccionada de material reciclável, de fácil preparo e manipulação, se mostrando capaz de atrair e infectar mosquitos de A. aegypti.

Palavras-chave: Aedes aegypti, garrafa PET, fungo entomopatogênico, atraente sintético.

\footnotetext{
1 Universidade Estadual do Norte Fluminense - Centro de Ciências e Tecnologias Agropecuárias - Laboratório de Entomologia e Fitopatologia, Av. Alberto Lamego, 2000, Campos dos Goytacazes-RJ, Brasil. E-mail: imad.saudecoletiva@gmail.com.

2 Universidade Estadual do Norte Fluminense - Centro de Ciências e Tecnologias Agropecuárias - Laboratório de Entomologia e Fitopatologia, Av. Alberto Lamego, 2000, Campos dos Goytacazes-RJ, Brasil. E-mail: biodepaula@yahoo.com.br.

3 Universidade Estadual do Norte Fluminense - Centro de Ciências e Tecnologias Agropecuárias - Laboratório de Entomologia e Fitopatologia, Av. Alberto Lamego, 2000, Campos dos Goytacazes-RJ, Brasil. E-mail: anderson.ribeirorj@yahoo.com.br.

4 Universidade Estadual do Norte Fluminense - Centro de Ciências e Tecnologias Agropecuárias - Laboratório de Entomologia e Fitopatologia, Av. Alberto Lamego, 2000, Campos dos Goytacazes-RJ, Brasil. E-mail: richard@uenf.br
} 